\title{
INTERESTERIFICAÇÃO ENZIMÁTICA NA OBTENÇÃO DE SUBSTITUTOS DA MANTEIGA DE CACAU
}

\author{
ALEXANDRE PORTE *
}

\begin{abstract}
Apresenta breve revisão bibliográfica sobre interesterificação química e enzimática, abordando os aspectos gerais e comparando seus usos. Enfoca também a produção de substitutos da manteiga de cacau a partir de óleos vegetais e outros alimentos por interesterificação enzimática.
\end{abstract}

\section{INTRODUÇÃO}

A cada dia cresce a preocupação com a qualidade dos alimentos industrializados que são consumidos. Por isso, nova demanda por produtos "naturais" e "nutritivos" tem impulsionado todas as áreas da indústria alimentícia na busca de processamentos mais brandos, que melhorem os produtos e ainda sirvam como apelo comercial. Neste sentido, métodos não convencionais de processamento, como o emprego de enzimas, em substituição a drásticos tratamentos térmicos e químicos na indústria de óleos e confeitaria, visando obtenção de substitutos da manteiga de cacau, vêm conquistando espaço na produção de alimentos.

\section{A INTERESTERIFICAÇÃO E SEUS USOS}

A interesterificação é um dos métodos de modificação de lipídios mais utilizados (WISDOM, 1984). Trata-se da substituição de ácidos graxos esterificados ao glicerol pela reação química entre um triacilglicerol e um ácido graxo ou entre dois triacilgliceróis. Com a formação de novo triglicerídio, novas propriedades organolépticas, físicas e químicas são adquiridas. MARANGONI \& ROUSSEAU (1995) definem-na como a substituição de ácidos graxos dentro e entre triglicerídios.

A interesterificação pode ser química ou enzimática. A interesterificação química, conhecida desde 1844, é o método de interesterificação mais empregado na indústria nos dias atuais (MARANGONI \& ROUSSEAU, 1995; ALLEN, 1996). É realizada por meio de bases fortes, ácidos, metais e, principalmente, alcóxidos de sódio (notadamente o metóxido de sódio), promovendo a migração não controlada e aleatória de ácidos graxos nos

* Nutricionista, Mestrando em Ciência e Tecnologia de Alimentos, Universidade Federal Rural do Rio de Janeiro (UFRRJ), Rio de Janeiro, Brasil. 
triglicerídios (MARANGONI \& ROUSSEAU, 1995; ALLEN, 1996). Pode ser classificada em aleatória e direta. Quando as reações ocorrem acima da temperatura de fusão do triglicerídio, que apresenta ponto de fusão mais elevado, todos os triacilgliceróis estarão disponíveis para reagirem aleatoriamente, caso contrário a mistura de triacilgliceróis se enriquece dele, cristalizando-o e separando-o da matéria-prima original (MARANGONI \& ROUSSEAU, 1995).

A interesterificação química é realizada em bateladas de 10-15 toneladas de reagente, em sistema de vácuo e muito baixo conteúdo de umidade $(0,01 \%)$. Ao final do processo, adiciona-se água a fim de neutralizar a reação. Após curto espaço de tempo, a água é, então, separada por centrifugação do produto (TOMBS, 1997). O tamanho do catalisador, a agitação, e principalmente, a temperatura, afetam o processo (MARANGONI \& ROUSSEAU, 1995). Por exemplo, as reações com metóxido de sódio e sódio metálico, que são os dois catalisadores mais aplicados, devem ocorrer entre $60-90{ }^{\circ} \mathrm{C}$ e $130{ }^{\circ} \mathrm{C}$, respectivamente (ALLEN, 1996).

A interesterificação é usada como método alternativo à hidrogenação de óleos vegetais para a produção de margarinas e similares (ADHIKARI \& ADHIKARI, 1992). Para isso, é empregado metóxido de sódio a $75-80{ }^{\circ} \mathrm{C}$ por 30 minutos, resultando em cristalização com boas propriedades organolépticas e menor faixa de fusão, melhorando o produto que unta alimentos e vasilhames a serem submetidos ao aquecimento em fornos. A interesterificação química também pode ser realizada com hidróxido de sódio, mas neste caso, necessita de temperaturas em torno de $150{ }^{\circ} \mathrm{C}$ para produzir margarinas com teores de ácidos graxos trans inferiores a 5\%. (LIST et al. 1995; MARANGONI \& ROUSSEAU, 1995; ALLEN, 1996; SCHMIDT et al. 1996).

As novas exigências dos consumidores e dos órgãos governamentais dos países desenvolvidos, por menor quantidade de aditivos alimentares e pela redução de tratamentos químicos dados aos produtos alimentícios, tem tornado mais atrativo o uso de enzimas (TOMBS, 1997).

As enzimas utilizadas na interesterificação enzimática são as lipases ou triacilglicerol hidrolases (EC 3.1.1.3) (TOMBS, 1997). Embora o maior interesse nas lipases seja a busca de enzimas resistentes a álcalis para uso em detergentes, na área de alimentos a modificação de óleos e gorduras por enzimas está se tornando uma das mais importantes tecnologias das indústrias de óleos e gorduras (TOMBS, 1997; KAWAHARA, 1993; MARANGONI \& ROUSSEAU, 1995). As lipases catalisam reações de hidrólise de triglicerídios, interesterificação, alcóolise e formação de ésteres de ceras ou de açúcares, podendo ser agrupadas em duas grandes classes. A primeira, ataca as ligações 1 e 3 dos triglicerídios, incluindo aqui as lipases pancreáticas e extracelulares de 
Aspergillus sp., Pseudomonas sp., Mucor sp., Rhizopus sp., C. viscosum, etc. A segunda, ataca as ligações 1, 2 e 3, sendo comum as lipases de Candida sp., Sthaphylococcus sp. e Geotrichum sp. (TOMBS, 1997; KAWAHARA, 1993; MARANGONI \& ROUSSEAU, 1995).

A interesterificação enzimática não afeta de modo adverso as concentrações de lipídios plasmáticos pelo rearranjo direto dos triglicerídios. Por isso, representa estratégia para a solidificação de óleos, tornando-se alternativa ao consumo de ácidos graxos trans produzidos durante a hidrogenação (NESTEL et al. 1996).

O uso de lipases para interesterificação enzimática foi descrito por vários autores em sistemas com baixo conteúdo de água, em batelada ou contínuo (WISDOM, 1984).

GHOSH \& BHATTACHARYYA (1997) interesterificaram com lipase 1,3 específica de Mucor miehei, durante 5 horas, a fração de alto ponto de fusão $\left(58{ }^{\circ} \mathrm{C}\right)$ da estearina fracionada do óleo de palma. Reduziram seu ponto de fusão conforme o óleo empregado como fonte de ácidos graxos insaturados para $37,5{ }^{\circ} \mathrm{C}$ (óleo de girassol), 38,9 ${ }^{\circ} \mathrm{C}$ (óleo de soja) e $39,6{ }^{\circ} \mathrm{C}$ (óleo de arroz). Os autores atribuíram este decréscimo no ponto de fusão à substituição de tripalmitina e outros triglicerídios trissaturados por triacilgliceróis insaturados. Tal fato tornou aproveitável a fração de alto ponto de fusão em alimentos livres de ácidos graxos trans, já que normalmente apenas a fração de baixo ponto de fusão $\left(35{ }^{\circ} \mathrm{C}\right)$ é empregada na obtenção de margarinas isentas de ácidos graxos trans. Outra aplicação da interesterificação enzimática destina-se a inserir ácidos graxos polinsaturados na síntese de glicerídios, como ácido eicosapentaenóico (EPA, 20:5) e ácido docosahexaenóico (DHA, 22:6), que reduzem as doenças do sistema cardiovascular, como trombose cerebral e aterosclerose (KAWAHARA, 1993; MARANGONI \& ROUSSEAU, 1995). Estes ácidos também apresentam qualidades antitumorais, anti-inflamatória e antiviral, além do EPA ser precursor de substâncias anti-agregatórias e o DHA compor a membrana fosfolipídica das células (SRIDHAR \& LAKSMINARAYANA, 1992; ZU-YI \& WARD, 1993). Tanto o EPA quanto o DHA podem ter suas sínteses prejudicadas na deficiência da atividade da enzima $\Delta 6$-desaturase, devendo-se ressaltar a importância da presença destes na alimentação. Contudo, a ingestão de óleos de peixes como fonte destes ácidos graxos poliinsaturados resulta no consumo adjacente de colesterol (SRIDHAR \& LAKSHMINARAYANA, 1992; ZU-YI \& WARD, 1993). Como a absorção destes ácidos é dependente de outros lipídios é possível que sua presença, em triacilgliceróis seja mais aproveitável do que em suplementos isolados, e ainda, sejam muito mais consumidos regularmente, devido a utilização diária de óleos comestíveis na preparação dos alimentos em, praticamente, todo o mundo. 
Na Índia, SRIDHAR \& LAKSHMINARAYANA (1992) esterificaram óleo de amendoim com EPA e DHA, substituindo os ácidos graxos saturados de cadeias longas normalmente presentes, como os ácidos araquídico (20:0), behênico (22:0) e lignocérico (24:0), que exercem atividade aterogênica. $A$ reação, que durou 4 horas com enzima estereoespecífica 1,3 de Mucor miehei incorporou 9,2\% de EPA e 7,4\% de DHA no óleo original.

TANAKA et al. (1994) sintetizaram triglicerídios contendo EPA e DHA, mediante intesterificação catalisada por enzima de Chromobacterium viscosum. Outros microrganismos, como a Candida antarctica são usados como produtores de enzimas, da mesma maneira que outros óleos, como o de canola e de soja hidrogenado são interesterificados (MARANGONI \& ROUSSEAU, 1995).

ZU-YI \& WARD (1993) utilizaram lipase de Mucor miehei para interesterificar, com sucesso, os óleos de milho, girassol, amendoim, oliva e soja, durante 12 horas.

A interesterificação também pode ser muito útil para garantir ingestão suficiente de ácidos graxos poliinsaturados, que são facilmente oxidáveis e termolábeis (KAWAHARA, 1993). Em contraste, de acordo com SRIDHAR et al. (1991a), as altas concentrações de ácidos graxos poliinsturados presentes nos óleos de amendoim, girassol, soja, linhaça (usado industrialmente e consumido em alguns lugares) e açafroa podem promover efeitos maléficos à saúde. Isto se deve ao fato dos ácidos graxos poliinsaturados decrescerem os níveis de LDL (lipoproteína de baixa densidade), mas também diminuírem as concentrações de HDL (lipoproteína de alta densidade), enquanto os ácidos graxos moninsaturados reduzem apenas a primeira (YODICE, 1990). Os efeitos maléficos provocados por altas concentrações de ácidos graxos poliinsaturados envolvem:

- aumento no risco de colelitíase (STURDEVANT et al. 1973);

- alteração na composição de membranas celulares (KING \& SPECTOR, 1978);

- redução nos níveis de HDL (VEGA et al. 1982);

- atuam como fator aterosclerótico (KUBOW, 1990);

- são oxidados e atuam como iniciadores e promotores na oncogênese (KUBOW, 1990).

O ácido oléico (ácido graxo monoinsaturado) pode ser tão benéfico quanto os ácidos graxos poliinsaturados, sem no entanto, afetar os níveis de HDL (MATTSON \& GRUNDY, 1985; KUBOW, 1990). Por isto, SRIDHAR et al. (1991a) interesterificaram com lipase 1,3 específica de Mucor miehei, em hexano, por 4 horas, os óleos de amendoim, girassol, soja, linhaça e açafroa para substituir parte dos ácidos graxos saturados e dos ácidos 
graxos poliinsaturados por ácido graxo monoinsaturado. No caso da soja, por exemplo, o ácido oléico aumentou sua concentração em 30\%.

O óleo de girassol (Sunola ${ }^{\circledR}$ ) produzido a partir de variante genética desta oleaginosa foi desenvolvido recentemente. Além de elevado conteúdo de ácido oléico apresentou estabilidade a oxidação e características adequadas para o uso em frituras (NESTEL et al. 1996).

KERMASHA et al. (1995) interesterificaram manteiga, usando lipase comercial obtida de Rhizopus niveus para substituir ácido palmítico de efeito hipercolesterolêmico, por ácido oléico.

Uma família de triacilgliceróis contendo um ácido graxo de cadeia curta (ácido acético, propiônico ou butírico) e outro de cadeia longa (predominantemente ácido esteárico) foi desenvolvida pelo grupo Nabisco nos Estados Unidos. A família Salatrim ${ }^{\circledR}$, obtida pela interesterificação pode ser útil como lipídios de baixas calorias para alimentos, apresentando características físicas desejáveis para uso industrial (HUANG et al. 1994; SMITH et al. 1994; SOFTLY et al. 1994).

Segundo HAUMANN (1994) 33\% do total de óleos usados no mundo são hidrogenados, enquanto $10 \%$ já são interesterificados.

Tanto a interesterificação química como a enzimática apresentam limitações e características atraentes sob o ponto de vista tecnológico, quando mutuamente comparados.

A Tabela 1 apresenta algumas vantagens e desvantagens entre ambos os processos.

\section{A INTERESTERIFICAÇÃO ENZIMÁTICA USADA PARA OBTER SUBSTITUTOS DA MANTEIGA DE CACAU}

Exemplo bem conhecido de modificação enzimática de óleos e gorduras é a produção de substitutos da manteiga de cacau. Óleos e gorduras que contêm ácido oléico na sua posição 2 são interesterificados com ácido palmítico ou ácido esteárico na presença de enzima esteoreoespecífica 1,3 (KAWAHARA, 1993).

A manteiga de cacau é um lipídio de alto valor comercial na produção industrial de chocolates. Apresenta ponto de fusão $\left(36{ }^{\circ} \mathrm{C}\right)$ e estrutura cristalina particulares, vitais para o seu uso, devido a mistura de palmitil, oleil, estearil, glicerol e 1,3-diestearil, 2-oleil, glicerol (CHANG et al. 1990; TOMBS, 1997). Em temperaturas abaixo de $26{ }^{\circ} \mathrm{C}$, a manteiga de cacau é 


\section{TABELA 1 - VANTAGENS E DESVANTAGENS MAIS IMPORTANTES ENTRE AS INTERESTERIFICAÇÕES QUÍMICA E ENZIMÁTICA}

\begin{tabular}{|c|c|c|c|}
\hline \multicolumn{2}{|c|}{ Interesterificação Química } & \multicolumn{2}{|c|}{ Interesterificação Enzimática } \\
\hline Vantagens & Desvantagens & Vantagens & Desvantagens \\
\hline $\begin{array}{c}\text { Catalisadores são mais baratos } \\
\text { (MARANGONI \& } \\
\text { ROUSSEAU, 1995) }\end{array}$ & & & $\begin{array}{l}\text { Lipases são mais caras } \\
\text { (TOMBS, 1997) }\end{array}$ \\
\hline \multirow[t]{2}{*}{$\begin{array}{l}\text { Há disponibilidade industrial de } \\
\text { equipamentos e procedimentos } \\
\text { operacionais prontos para a } \\
\text { implantação (MARANGONI \& } \\
\text { ROUSSEAU, 1995) }\end{array}$} & & & $\begin{array}{c}\text { Necessita o } \\
\text { desenvolvimento e } \\
\text { otimização de } \\
\text { biorreatores adequados }\end{array}$ \\
\hline & $\begin{array}{l}\text { Catalisadores } \\
\text { podem ser } \\
\text { explosivos } \\
\text { (ALLEN, 1996) }\end{array}$ & $\begin{array}{c}\text { Sem riscos de } \\
\text { explosão (ALLEN, } \\
\text { 1996) }\end{array}$ & \\
\hline \multicolumn{4}{|l|}{$\begin{array}{c}\text { Quando comparado com a } \\
\text { interesterificação de enzimas } \\
\text { não estereoespecíficas (como a } \\
\text { de Candida cylindracae), } \\
\text { diferenças mínimas são } \\
\text { encontradas (MARANGONI \& } \\
\text { ROUSSEAU, 1995) }\end{array}$} \\
\hline \multirow[t]{5}{*}{$\begin{array}{c}\text { É mais rápida, durando de } 30 \text { a } \\
60 \text { minutos (ALLEN, 1996) }\end{array}$} & & & $\begin{array}{l}\text { Demanda horas } \\
\text { (ALLEN, 1996) }\end{array}$ \\
\hline & $\begin{array}{c}\text { Perda do flavour } \\
\text { característico da } \\
\text { manteiga } \\
\text { (MARANGONI } \\
\text { \& ROUSSEAU, } \\
\text { 1995) }\end{array}$ & & \\
\hline & $\begin{array}{l}\text { Geralmente são } \\
\text { exigidas } \\
\text { condições mais } \\
\text { enérgicas }\end{array}$ & $\begin{array}{l}\text { Exige condições } \\
\text { brandas de } \\
\text { operacionalização }\end{array}$ & \\
\hline & & $\begin{array}{l}\text { Estereoespecificidade } \\
\text { permite } \\
\text { transformações } \\
\text { inalcançáveis pelo } \\
\text { método químico } \\
\text { (MARANGONI \& } \\
\text { ROUSSEAU, 1995) }\end{array}$ & \\
\hline & $\begin{array}{l}\text { Grande produção } \\
\text { de produtos } \\
\text { colaterais } \\
\text { (WISDOM, 1984; } \\
\text { CHAN et al.1990) }\end{array}$ & $\begin{array}{l}\text { Reduzida produção de } \\
\text { produtos colaterais } \\
\text { (WISDOM, 1984; } \\
\text { CHAN et al. 1990) }\end{array}$ & \\
\hline $\begin{array}{l}\text { Não produzem ácidos graxos } \\
\text { trans (ALLEN, 1996) }\end{array}$ & & $\begin{array}{l}\text { Não produzem ácidos } \\
\text { graxos trans (ALLEN, } \\
1996)\end{array}$ & \\
\hline
\end{tabular}


dura e quebradiça (CHANG et al., 1990; SRIDHAR et al. 1991). Quando ingerida, derrete completamente na boca propiciando agradável sensação. Estas propriedades são ocasionadas por sua incomum composição de glicerídios. Diferente dos outros óleos e gorduras, a manteiga de cacau contém poucos triglicerídios e três destes constituem $80 \%$ do seu peso, sendo que o palmitil, oleil, estearil, glicerol e o 1,3-diestearil, 2-oleil, glicerol correspondem a $52 \%$ e $18,4 \%$ do total, respectivamente (CHANG et al. 1990).

O óleo de palma, comumente descrito como precursor de substitutos de manteiga de cacau, conta com o 1,3-dipalmitil, 2-oleil, glicerol como triacilglicerol predominante e por interesterificação enzimática, usando ácido esteárico ou etilestearato, forma mistura de palmitil, oleil, estearil, glicerol e 1,3-diestearil, 2-oleil, glicerol, os principais componentes responsáveis pelo baixo ponto de fusão da manteiga de cacau (MARANGONI \& ROUSSEAU, 1995).

MOJOVIC et al. (1993) interesterificaram a fração média do óleo de palma com ácido esteárico em n-hexano, mediante triacilglicerol hidrolase de Rhizopus arrhizus e o produto obtido mostrou-se similar à manteiga de cacau. De acordo com estes autores, a adição de lecitina de soja desengordurada elevou significativamente a conversão do substrato. Tal fato foi atribuído ao efeito protetor sobre a enzima contra solvente apolar, o que aumentou a difusão do produto no microambiente da enzima.

Um dos maiores problemas para a ação das lipases é a água, pois ao mesmo tempo que pequenas concentrações são necessárias para manter a integridade da enzima, níveis maiores provocam hidrólise dos triglicerídios. Por isso, é bom manter o nível de água o mais baixo possível, e como este variará durante o processo, é preciso monitorá-lo cuidadosamente. Para contornar o problema dos níveis de água, os lipídios e a enzima são dissolvidos em heptano ou outro hidrocarboneto de viscosidade adequada, para permitir razoável tempo de vida das enzimas, mas a toxicidade do solvente passa a ser o empecilho. Também se usa manteiga fundida como substituta do solvente no processo de interesterificação (BORNAZ et al., 1994; TOMBS, 1997).

CHANG et al. (1990) interesterificaram azeite de oliva e óleo de semente de algodão hidrogenados com lipase 1,3-esteroespecífica do fungo Mucor miehei, durante 4 horas, a $70{ }^{\circ} \mathrm{C}$ e obtiveram rendimento de $19 \%$ baseado no peso dos óleos. CHONG et al. (1992) obtiveram 25\% de rendimento baseado no peso dos óleos, pela ação desta mesma enzima sobre o óleo de palma com temperaturas entre 60 e $70^{\circ} \mathrm{C}$.

BYSTROM \& HARTEL (1994) usaram lipase de Candida rugosa sob pressões supercríticas em dióxido de carbono, para obter substituto da manteiga de cacau a partir de frações do leite. Empregaram este novo 
produto na fabricação de chocolates, substituindo 10 a $20 \%$ da manteiga de cacau, contudo, os chocolates tornaram-se mais moles que o controle e os autores concluíram que o processo precisa ser aperfeiçoado para obter um produto adequado e funcional.

SRIDHAR et al. (1991b) tentaram interesterificar uma variedade de manga como substituto da manteiga de cacau, empregando triacilglicerol hidrolases fúngica de Mucor miehei imobilizada em resina de troca iônica microparticulada. Apesar de terem conseguido aumentar a quantidade de ácido palmítico no substrato, não lograram decrescer os conteúdos naturais de linoleatos, afetando o ponto de fusão do produto.

Os substitutos da manteiga de cacau podem apresentar melhor resistência ao calor e melhor comportamento de fusão do que a própria manteiga de cacau (KAWAHARA, 1993).

Enzimas extracelulares de Aspergillus sp. específicas para as ligações 1,3 são vendidas comercialmente e sua solução é precipitada com acetona resfriada em suporte de terra de diatomácea. Neste as enzimas tornam-se fixas sem se solubilizarem no solvente, mas podem ser dissolvidas e lavadas para fora do suporte, usando-se água e soluções aquosas (WISDOM, 1984). A reação dura várias horas, sendo necessário remover a seguir o excesso de 1,2,3-triestearil glicerol e 1,2,3-tripalmitil glicerol para tornar o óleo de palma mais parecido com a manteiga de cacau (TOMBS, 1997).

A terra de diatomácea (de nome comercial diatomite) é obtida a partir de restos de algas, pertencentes à família das diatomáceas, fossilizados em sílica. O tratamento do material bruto inclui: lavagem, moagem e aquecimento com um sal, ao fim do qual servirá como suporte para imobilização de enzimas. Nos suportes, as lipases podem ser facilmente removidas da mistura e reutilizadas, logo, a escolha do suporte em que a enzima será imobilizada também é importante, pois determina o acesso da enzima ao substrato, e portanto, bom grau de interesterificação (WISDOM, 1984; CHANG et al. 1990).

$\mathrm{Na}$ prática, as características do fluxo no meio de suporte é de grande importância no projeto das colunas dos reatores, e isto é segredo comercial (TOMBS, 1997). O tempo de reação, a ser determinado em função de uma série de variáveis (temperatura, suporte, solvente, substrato, etc.) também é fundamental. Existe o tempo ótimo no qual maior concentração de palmitil, oleil, estearil, glicerol é produzida.

Segundo CHAN et al. (1990) as enzimas são estereoespecíficas, mas não são ácido específicas, permitindo a produção de até 18 compostos colaterais, em pequenas quantidades. 
As triacilglicerol hidrolases apresentam relativamente pouca especificidade, mas é difícil determiná-las pelo método convencional porque este se baseia na medição da concentração de substrato, e no caso das lipases, outros fatores como a área de superfície disponível também interferem. Por isso, uma das mais atrativas possibilidades para as lipases em alimentos é o surgimento de enzimas com especificidade por determinados ácidos graxos. A lipase do Geotrichum sp., por exemplo, hidrolisa triacilgliceróis que contenham o ácido oléico, liberando-o (MARANGONI \& ROUSSEAU, 1995; TOMBS, 1997).

A estabilidade das triacilglicerol hidrolases é outro ponto a ser considerado. A lipase pancreática de porco (a única lipase que teve sua cadeia polipeptídica totalmente seqüenciada) é estável a $100{ }^{\circ} \mathrm{C}$ por várias horas. Em muitos casos, contudo, a termolabilidade pode ser desejada, uma vez que se torna conveniente terminar o processo com aquecimento (TOMBS, 1997).

\section{CONCLUSÂO}

À medida que enzimas mais estáveis e baratas forem sendo introduzidas e biorreatores enzimáticos de grande escala desenvolvidos e otimizados, cada vez mais aumentará o uso desta tecnologia pela indústria de óleo.

Novas possibilidades também irão surgindo conforme as enzimas ácido específicas venham a ser biossintetisadas ou extraídas, pois permitem o aumento na precisão das reações, diminuindo ainda mais a formação de produtos colaterais e a necessidade de uso de técnicas adicionais de separação, além de aumentar o rendimento.

Apesar de ter sido descoberta há mais de um século e meio, ainda existem muitos aspectos a serem elucidados e desenvolvidos neste promissor método de modificação de triglicerídios.

\section{Abstract}

This article presents a brief review about chemical and enzymatic intersterification, general aspects and uses. It also focus the production of cocoa butter substitutes from vegetables oils and other foods by enzymatic intersterification.

\section{REFERÊNCIAS BIBLIOGRÁFICAS}

1 ADHIKARI, S., ADHIKARI, J. Detection of interesterified fats in hydrogenated fats. Journal of the American Oil Chemistry Society, v. 69, n. 10, p. 1051-1053, 1992. 
ALLEN, D. A. Interesterification: a vital tool for the future? Lipid Technology, Jan., p. 11-15, 1996.

BORNAZ, S., FANNI, J., PARMENTIER, M. Limit of the solid fat content modification of butter. Journal of American Oil Chemistry Society, v. 71, n. 12, p. 1373-1380, Dec.1994.

BYSTROM, C. E., HARTEL, R. W. Evaluation of milk fat fractionation and modification techniques for creating cocoa butter replacers. Lebensmittel Wissenschaft und Technologie, v. 27, n. 2, p. 142-156, 1994.

CHANG, M. K., ABRAHAM, G., JOHN, V. T. Production of cocoa butter-like fat from interesterification of vegetable oils. Journal of American Oils Chemistry Society, v. 67, n. 11, p. 832-834, Nov. 1990.

CHONG, C. N., HOH, Y. M., WANG, C. W. Fractionation procedures for obtaining cocoa butter-like fat from enzymatically interesterified palm olein. Journal of American Oils Chemistry Society, v. 69, n. 2, Feb., 1992.

7 GHOSH, S., BHATTACHARYYA, D. K. Utilizations of high-melting palm stearin in lipase-catalyzed interesterification with liquid oils. Journal of American Oils Chemistry Society, v. 74, n. 5, p. 589-592, 1997.

HAUMANN, B. F. Tools: hydrogenation, interesterification. Inform, v. 5, n. 6, p. 668-678, 1994.

9 HUANG, A. S., DELANO, G. M., PIDEL, A., JANES, L. E., SOFTLY, B. J., TEMPLEMAN, G. J. Characterization of triaciylglycerols in satured lipid mixtures with application to SALITRIM 23 CA. Journal of Agricultural and Food Chemistry, v. 42, n. 2, p. 453460, 1994. Technology, v. 4, n. 6, p. 663-667, Jun. 1993.

11 KERMASHA, S., SAFARI, M., GOETGHEBEUR, M. Interesterification of butter fat by lipase from Rhizopus niveus in cosurfactant-free microemulsion system. Applied-Biochemistry-andBiotechnology, v. 53, n. 3, p. 229-244, 1995.

12 KING, M. E., SPECTOR, A. A. Effect of specific fatty acyl enrichments on membrane physical properties detected with a spin label probe. Journal of Biologycal Chemistry, v. 253, p. 6493-6501, 1978. 
Food Science and Technology, v. 1, p. 67-71, 1990.

14 LIST, G. R., MOUNTS, T. L., ORTHOEFER, F., NEFF, W. E. Margarine and shortening oil by interesterification of liquid and trisatured triglycerides. Journal of American Oil Chemistry Society. v. 72, n. 3, p. 379-382, 1995.

15 MARANGONI, A. G., ROUSSEAU, D. Engineering triacylglicerols: the role of interesterification. Trends in Food Science and Technology, v. 6, p. 329-336, Oct. 1995.

16 MATTSON, F.H., GRUNDY, S.M. Comparison of effects of dietary satured, monounsatured and polyunsaturated fatty acids on plasma lipids and lipoproteins in man. Journal of Lipids Research, v. 26, p. 194-202, 1985.

17 MOJOVIC, L., SILER-MARINKOVIC, S., KUKIC, G., VUNJAKNOVAKOVIC, G. Enzyme and Microbial Technology, v. 15, n. 5, p. 438-443, 1993.

NESTEL, P., NOAKES, M., CLIFTON, P. Fats for the food industry: implications for cholesterol-lowering. Lipids, v. 31, p. 65-69, 1996. (Suplemento).

19 SCHMIDT, S., HURTOVA, S., ZEMANOVIC, J., SEKRETAR, S., SIMON, P., AINSWORTH, P. Preparation of modified fats from vegetable oil and fully hydrogenated vegetable oils by randomization with alkali catalysts. Food Chemistry, v. 55, n. 4, p. 343-348, 1996.

SMITH, R. E., FINLEY, J. W., LEVEILLE, G. A. Overview of Salatrim, a family of low-calorie fats. Journal of Agricultural and Food Chemistry, v. 42, n. 2, p. 432-434, 1994.

21 SOFTLY, B. J., HUANG, A. S., FINLEY, J. W., PETERSHEIM, M., YARGER, R. G., CHRYSAM, M. M., WIEZOREK, R. L., OTTERBURN, M. S., MANZ, A., TEMPLEMAN, G. J. Composition of representative Salatrim fat preparations. Journal of Agricultural and Food Chemistry, v. 42, n. 2, p. 461-467, 1994.

22 SRIDHAR, R., LAKSHMINARAYAMA, G., KAIMAL, T. N. B. Modification of selected edible vegetable oils to high oleic oils by lipase-catalyzed ester interchange. Journal of Agricultural Food Chemistry, v. 39, p. 2069-2071, 1991a. 
SRIDHAR, R., LAKSHMINARAYAMA, G., KAIMAL, T. N. B. Modification of selected Indian vegetable fats into cocoa butter substitutes by lipase-catalyzed ester interchange. Journal of American Oils Chemistry Society, v. 68, n. 10, p. 726-730, 1991b.

24 SRIDHAR, R., LAKSHMINARAYAMA, G. Incorporation of eicosapentaenoic and docosahexaenoic acids into groundnut oil by lipase-catalyzed ester interchange. Journal of American Oil Chemistry Society, v. 69, n. 10, p. 1041-1042, Oct. 1992.

25 STURDEVANT, R. A. L., PEARCE, M. L., DAYTON, S. Increased prevalence of cholelithiasis in men ingesting a serum cholesterol lowering diet. New England Journal of Medicine, v. 288, p. 2427, 1973.

TANAKA, Y., HIRANO, J., FUNADA, T. Synthesis of docosahexaenoic acid-rich triglyceride with imobilized Chromobacterium viscosum lipase. Journal of the American Oil Chemistry Society, v. 71, n. 3, p. 331-334, 1994.

27 TOMBS, M. P. Enzymes in the processing of fats and oils. In: ENZYMES in food processing. 2.ed. London : Blackie Academic \& Professional, 1997. p. 268-291.

VEGA, G. L., GROSZEK, E., WOLF, R., GRUNDY, S. M. Influence of polyunsatured fats on compostion of plasma lipoproteins and apolipoproteins. Journal of Lipids Research, v. 23, p. 811-822, 1982.

WISDOM, R. A., DUNNIL, P., LILLY, M. D., MACRAE, A. Enzymic interesterification of fats: factors influencing the choice of support for immobilized lipase. Enzyme Microbiology Technology, v. 6, p. 443-446, Oct. 1984.

30 YODICE, R. Nutritional and stability characteristics of high oleic sunflower seed oil. Fat Science and Technology, v. 92, p. 121$126,1990$.

31 ZU-YI, L., WARD, O. P. Enzyme catalysed production of vegetable oils containing omega-3 polyunsaturated fatty acid.

Biotechnology Letters. v. 15, p. 185-188, Feb. 1993. 